\title{
RACIONALISMO CRÍTICO, VERDAD CIENTÍFICA Y FALIBILISMO MORAL EN LA EPISTEMOLOGÍA DE KARL POPPER
}

\section{Critical rationalism, scientific truth, and moral fallibilism in Karl Popper's epistemology}

Ángel Gómez Navarro

Docente principal del Departamento Académico de filosofía y teología de la Facultad de Psicología y Humanidades de la UNIFE y miembro del grupo de investigación en Filosofía Social (GIFS) de la PUCP.agomez@unife.edu.pe.https://orcid.org/0000-0003-4768-1950

\section{RESUMEN}

En el presente ensayo se analiza el criterio epistémico del falibilismo dentro del racionalismo crítico y realismo científico que configuran la epistemología de Karl Popper. El falibilismo se evidencia, especialmente al momento de evaluar no sólo a las teorías científicas sino también a las teorías morales o diversas concepciones de bien, con el propósito de determinar sus pretensiones de verdad en el marco de una sociedad plural y democrática.

\section{Palabras clave:}

Falibilismo, racionalismo crítico, teorías, verdad, epistemología

\begin{abstract}
In this essay the epistemic criterion of fallibilism is analyzed within the critical rationalism and scientific realism that make up the epistemology of Karl Popper. Fallibilism becomes evident especially when evaluating not only scientific theories but also moral theories or various conceptions of good, in order to determine their claims to truth in the context of a plural and democratic society.
\end{abstract}

\section{Keywords:}

Fallibilism, critical rationalism, theories, truth, epistemology 
La epistemología de Karl Popper se puede definir como racionalismo crítico porque busca producir conocimiento a partir de una actitud crítica, anti dogmática, que cuestiona las propias posiciones y argumentaciones tratando de saber si están erradas o si son ideas preconcebidas o aceptadas acríticamente como verdaderas. Aprender esta actitud racional es la que puede permitir el avance de la ciencia y logar los conocimientos científicos que necesitamos para comprender y explicar el mundo. En tal sentido, la actitud científica es una actitud racionalista en la medida que busca, junto a otros y mediante el debate, alcanzar la verdad objetiva de los fenómenos que se estudia. En efecto, el mismo Popper señala que "lo que he llamado racionalismo crítico... no es una tesis, no es una teoría, no es un dogma. Es la actitud según la cual, si nos dedicamos a los problemas de modo crítico, podemos aprender" (citado por Artigas: 1998, 34-37).

Este racionalismo crítico es al mismo tiempo un realismo científico ya que busca producir conocimientos objetivos verosímiles siguiendo la refutación como criterio metodológico, lo cual desafía las limitaciones de nuestras formas de razonar científicamente y el alcance que tienen las pruebas experimentales o evidencias empíricas.

En su obra titulada la sociedad abierta y sus enemigos (2006), Popper se refiere a esta actitud de razonabilidad como exigencia epistémica del racionalismo crítico:

Podríamos decir, entonces, que el racionalismo es una actitud en que predomina la disposición a escuchar los argumentos críticos y aprender de la experiencia... En esta actitud no se desecha a la ligera la esperanza de llegar, mediante la argumentación y la observación cuidadosa a algún tipo de acuerdo con respecto a múltiples problemas de importancia y, aun cuando las exigencias e intereses de unos y otros puedan hallarse en conflicto, a menudo es posible razonar los distintos puntos de vista y llegar — quizá mediante el arbitraje- a una transacción que, gracias a su equidad, resulta aceptable para la mayoría, sino para todos. En resumen, la actitud racionalista o, como quizá pudiera llamarse, la «actitud de la razonabilidad», es muy semejante a la actitud científica, a la creencia de que en la búsqueda de la verdad necesitamos cooperación y que, con la ayuda del raciocinio, podremos alcanzar, con el tiempo, algo de objetividad (2006, p. 369-370).

La epistemología popperiana incluye también el criterio de falsación, criterio que no pretende probar la verdad de una teoría, pues una evidencia empírica posterior puede refutarla. En realidad, la falsación popperiana es un tipo de contrastación que nos permite demarcar aquello que es ciencia o conjunto de teorías científicas respecto de las que simplemente son apreciadas como teorías pseudocientíficas, lo cual exige desarrollar las respectivas justificaciones lógicas de sus enunciados observacionales.

Pero el racionalismo crítico popperiano no sólo se refiere a la filosofía y metodología de la ciencia sino también a la filosofía social y política. Para ambos casos, Popper considera la idea de falibilidad o falibilismo como una actitud moral que le permite a la 
actitud crítica encontrar la adaptación de las estructuras cognitivas del sujeto cognoscente frente a los problemas que se van planteando sucesivamente (González: 2004).

Por otro lado, la verdad científica para Popper se presenta como un ideal regulativo de las prácticas científicas en su afán por establecer conocimientos científicos válidos. Se trata de una verdad objetiva, donde la aseveración teórica concuerde con los hechos, lo cual no siempre podemos lograr y que, sin embargo, la ciencia debe buscar pues su finalidad es precisamente explicar la complejidad de los hechos y en muchos casos darles solución cuando tales hechos nos aquejan. Esta comprensión de verdad se asocia muy bien con la visión popperiana del realismo ontológico -especialmente en las ciencias de la naturaleza-, es decir, la existencia en sí misma de un mundo que nos trasciende y que, por lo mismo, no es que lo construimos socialmente, sino que ha de ser descubierto, descrito, explicado y predicho. Esto no significa que las teorías científicas reflejen exactamente la realidad, sino que presuponen la existencia de una realidad a la que podemos aproximarnos describiéndola cada vez más en modo adecuado mediante ensayo-error.

Por tanto, la verdad científica como ideal regulativo de toda actividad científica, que se sustenta en la realidad es al mismo tiempo una exigencia ética, es decir, un valor ético que se entronca con el principio de la falibilidad ya que las teorías científicas tienen siempre un carácter hipotético y no podemos renunciar a la autocrítica, pues nuestra racionalidad limitada puede caer en la trampa del psicologismo, idealismo, positivismo, etc.
Los argumentos de Popper a favor de la falibilidad epistémica derivan del carácter conjetural de nuestro conocimiento y de la posibilidad de que podemos equivocarnos (Errare hominum est). Y este es uno de los principios base de todo racionalismo crítico y científico que nos ayuda en la aproximación hacia la verdad de lo que observamos desde nuestras respectivas prácticas de investigación.

Popper plantea el principio del falibilismo al insistir en el carácter hipotético de la ciencia. Asimismo, tanto el falibilismo como la falsación popperiana pueden ser considerados como las dos caras de una misma moneda, en donde el primero se refiere a la posibilidad de error respecto de los enunciados que plantean las teorías científicas y, la segunda, trata de someter las hipótesis o conjeturas a una negación (no verificación) o refutación para ser eliminado, asumido o reemplazado por otra hipótesis.

Sin embargo, de esto no se puede inferir que el falibilismo popperiano se vincule con el relativismo epistémico, aunque ciertamente Popper se opone a la posibilidad de lograr una certeza absoluta en el conocimiento científico, pues como he mencionado, la verdad científica funciona como ideal regulativo de toda investigación. En su libro Conjeturas y refutaciones (1991), el filósofo vienés señala lo siguiente:

... Una gran ventaja de la teoría de la verdad objetiva o absoluta es que nos permite afirmar, con Jenófanes, que buscamos la verdad, pero que puede suceder que no sepamos si la hemos hallado o no; que no tenemos ningún criterio para establecer la verdad, no obstante 
ello, nos dejamos guiar por la idea de la verdad como principio regulador (como habrían dicho Kant o Pierce); y que, aunque no hay ningún criterio general mediante el cual reconocer la verdad, excepto quizás la verdad tautológica, hay algo similar a criterios de progreso hacia la verdad... (1991, p. 276-277).

En una de sus últimas obras, En busca de un mundo mejor (1995), Popper se refiere al falibilismo enunciando tres principios epistemológicos:

1. El principio de falibilidad: que consiste en reconocer precisamente que quizás yo estoy equivocado y que quizás tú tienes razón, pero que también es posible que ambos extremos estén equivocados.

2. El principio de discusión racional: pues deseamos sopesar, de forma tan impersonal como sea posible, las razones a favor y en contra de una teoría [...].

3. El principio de aproximación a la verdad: En una discusión que evite los ataques personales, casi siempre podemos acercarnos a la verdad [...].

Como he mencionado, estos principios epistémicos son también principios y actitudes ético-morales, en efecto, implican también, entre otras cosas, tolerancia y reconocimiento del otro: parafraseando a Popper lo que sostiene en La responsabilidad de vivir (1995), podemos decir que si yo espero aprender de ti, y si tú deseas aprender en interés de la verdad, yo tengo no sólo que tolerarte sino también reconocerte como alguien potencialmente igual; la unidad e igualdad potencial de todos constituye en cierto modo un requisito previo de nuestra disposición a discutir racionalmente las cosas (1995, p. 255).

La defensa popperiana del falibilismo (que no es relativismo) se justifica no sólo porque busca promover la actitud crítica y la honestidad respecto de los límites de los conocimientos científicos -sin que eso signifique renunciar a la verdad objetiva-, sino que también pretende evitar posiciones dogmáticas y autoritarias que Popper encuentra en las doctrinas historicistas occidentales consideradas como pseudocientíficas tal como se pueden apreciar en sus obras: La sociedad abierta y sus enemigos (2006) y La miseria del historicismo (2002). De ahí que el falibilismo sea también una actitud moral, cuya ausencia puede causar daño y sufrimiento en poblaciones enteras.

En consecuencia, los principios que subyacen a cualquier discusión racional que busca la verdad no sólo son principios epistémicos, sino también de 'eticidad o moralidad', pues exigen tolerancia y reconocimiento como condición de posibilidad no sólo para la elección de teorías científicas, sino también para la justificación de las teorías morales (incluso políticas y teológicas), lo cual puede ayudar a una convivencia democrática deseable e incluso a la transformación gradual de la sociedad y al mejoramiento funcional de las instituciones gubernamentales.

Sin embargo, Popper nos advierte que es más fácil llegar a un acuerdo razonable acerca de los males existentes y de los medios para combatirlos, que al propio ideal de bien que buscamos y a los medios para concretizarlo. Por ello es necesario el empleo de la razón, en lugar de la pasión y la violencia, especialmente para justificar las comprensiones de bien o teorías morales y políticas. "Siempre 
existirá la posibilidad de llegar a una transacción razonable de las partes y, por consiguiente, de alcanzar las mejoras mediante métodos democráticos". En efecto, los individuos experimentan dificultades al momento de juzgar las diversas comprensiones de bien que coexisten entre nosotros, pues no es fácil llegar a dar razones concluyentes en favor de alguna teoría (moral, política o teológica), y aunque muchos pueden estar dispuestos a tolerar las creencias de los otros, no están listos para tolerar las conductas o prácticas sociales que se derivan de tales creencias.

Defender la igualdad y la libertad de los individuos implica no sólo una justificación de la concepción ética elegida, sino también un compromiso personal de luchar contra toda forma de tiranía, dogmatismo e imposición de formas de gobierno que atentan contra el ideal de una libertad legítima.

La defensa de estos principios no significa que toda democracia tenga el deber de hacer que los hombres sean felices. Para Popper, la exigencia de la ética y la política humanista radica en luchar contra el sufrimiento y no tanto en favorecer a la felicidad de todos los hombres. Y frente a la exigencia del utilitarismo de buscar mayor felicidad para el mayor número de gente, Popper propone buscar "la menor cantidad de dolor para todos", pues considera que la felicidad es un asunto menos urgente que la necesidad de ayudar a los que sufren. Por tanto, es peligroso que los políticos tengan como ideal querer hacer felices a los pueblos.

Veamos lo que él mismo nos dice:

Pero de todos los ideales políticos quizás el más peligroso sea el de querer hacer felices a los pueblos.
En efecto, lleva invariablemente a la tentativa de imponer nuestra escala de valores 'superiores' a los demás para hacerles comprender lo que a nosotros nos parece que es de la mayor importancia para su felicidad... la tentativa de llevar el cielo a la tierra produce como un resultado inevitable el infierno. Ello engendra la intolerancia, las guerras religiosas y la salvación de las almas mediante la inquisición... Nuestra obligación es ayudar a aquellos que necesitan ayuda, pero no la de hacer felices a los demás... (2006, p. 419).

En suma, los principios epistémicos planteados por Popper, que aquí solo hemos esbozado, son también como mínimos éticos que se sustentan en el principio de la falibilidad, con lo cual quedaría demostrado que el falibilismo no solo nos puede orientar en la elección de las mejores teorías científicas sino también de las teorías ético-morales. Esto significa que los aspectos cruciales de la epistemología de Popper no pueden comprenderse sin una referencia a sus aspectos éticos y políticos; y a su vez, tales cuestiones ético-políticas apuntan necesariamente a su visión falibilista del conocimiento general y particular.

De esto se infiere que las diversas concepciones de bien (morales, políticas y religiosas), deben admitir la posibilidad de que pueden estar erradas o lejos de la verdad. Es decir, cada uno puede creer firmemente en la verdad de su concepción de bien, pero a su vez se debe tener la capacidad de aceptar de que las otras personas al ser también racionales y razonables pueden tener algo de razón o estar en un proceso de aproximación a la verdad no necesariamente tan lejana. 
En el campo de la moral muchas veces es casi imposible dar un juicio de valor debido no solo a la diversidad de concepciones de bien y a las limitaciones y condicionamientos del conocimiento humano, sino también a las numerosas preguntas abiertas que tales concepciones morales generan y que hace que surjan repreguntas, nuevos intentos de respuesta o nuevas conjeturas.

Esto sin embargo no significa asumir la actitud meramente escéptica, pues la actitud falibilista consiste tan solo en reconocer que siempre podemos errar en nuestra elección y, por tanto, en nuestra justificación racional. Es decir, no implica creer que no puede existir una fundamentación objetiva de las normas morales. En todo caso, un escéptico debería considerar su concepción de bien como una hipótesis o conjetura. Y frente al relativismo que afirma la no existencia de una justificación objetiva de tales normas sino solo una validez relativa, habría que sostener que tal posición se encuentra también limitada y condicionada por las serias dificultades que surgen cuando alguien pretende dar un juicio de valor objetivo.

En el campo de la moral muchas veces es casi imposible dar un juicio de valor debido no solo a la diversidad de concepciones de bien y a las limitaciones y condicionamientos del conocimiento humano, sino también a las numerosas preguntas abiertas que tales concepciones morales generan y que hace que surjan repreguntas, nuevos intentos de respuesta o nuevas conjeturas.

En conclusión, el falibilismo moral popperiano establece un puente entre los criterios epistémicos y las prácticas sociales, lo cual nos ayuda a evitar que, en nombre de una concepción de bien, nobles sentimientos o ideales de vida buena se realicen numerosos crímenes que afectan seriamente a nuestras sociedades democráticas. Popper lo ilustra así:

Las principales perturbaciones de nuestro tiempo -y no niego que vivimos en tiempos perturbadosno se deben a nuestra perversidad moral, sino, por el contrario, a nuestro entusiasmo moral a menudo mal dirigido: a nuestra ansiedad por mejorar el mundo en el que vivimos. Nuestras guerras son, fundamentalmente, guerras religiosas; son guerras entre teorías rivales acerca de la manera de establecer un mundo mejor. Y nuestro entusiasmo moral se halla a menudo mal dirigido porque nos damos cuenta de que nuestros principios morales, sin duda muy simples, son con frecuencia difíciles de aplicar a las complejas situaciones humanas y políticas a las que nos sentimos obligados a aplicarlos (1991, p. 438).

Asimismo, el falibilismo como actitud moral, práctica, asume los límites de la razón humana con una firme convicción realista y anti relativista y se constituye en una muy buena alternativa al logicismo o neopositivismo, razón por lo que algunos han tildado a Popper de ser un irracionalista contemporáneo. El falibilismo popperiano es la columna vertebral de su epistemología y su visión ético-política, el cual no renuncia a la verdad como máximo valor epistémico, sino a la obsesión por la certeza total, no es escéptico ni relativista, sino que, más bien, apuesta por una nueva forma de concebir a la razón basada en el sentido 
común crítico, y con la convicción de que podemos errar en nuestras conjeturas, tal actitud es la que debe orientar todas nuestras prácticas investigativas.

\section{REFERENCIAS BIBLIOGRÁFICAS}

Artigas, M. (1998). Lógica y ética en Karl Popper. Pamplona: EUNSA.

González, W (ed.) (2004.) Karl Popper: Revisión de su legado. Madrid: Unión Editorial.

Miller, D. (Comp.) (1995). Popper. Escritos selectos. México. Fondo de Cultura Económica.

Popper, K. (2006). La sociedad abierta y sus enemigos. Barcelona: Paidós.
Popper, K. (2002). La miseria del historicismo. Madrid: Alianza Editorial.

Popper, K. (2010). Conocimiento objetivo. Un enfoque evolucionista. Madrid: Tecnos.

Popper, K. (1972). Conjeturas y refutaciones. El Desarrollo del conocimiento científico. Barcelona: Paidós.

Popper, K. (1994). En busca de un mundo mejor. Barcelona: Paidós.

Popper, K. (1995). La responsabilidad de vivir. Escritos sobre política, historia y conocimiento. Barcelona: Paidós.

Verdugo, C. (2001). Selección de escritos sociopolíticos de Karl Popper. Santiago de Chile: Centro de Estudios Públicos.

Fecha de recepción: 15-04-2020

Fecha de aceptación: 13-05-2020 